\title{
Os caminhos e descaminhos de A Corte do Norte, romance de Agustina Bessa-Luís: uma leitura
} neobarroca

\author{
Marcelo Brandão Mattos \\ (Universidade Federal Fluminense)
}

\section{RESUMO}

O artigo propõe uma leitura do romance $A$ Corte do Norte, de Agustina BessaLuís, como exemplar de uma estética neobarroca. A fragmentação do discurso, rompendo com a unidade narrativa, e a dispersão da verdade, tomada como uma multiplicidade de versões, são os caminhos de leitura que nos conduzem ao labirinto proposto pela autora: imagem de um mundo descentrado.

PALAVRAS-CHAVE: Verdade; dissipação; fragmentação; estética neobarroca

\section{ABSTRACT}

The article proposes a reading of the novel $A$ Corte do Norte, of Agustina BessaLuís, like an example of neo-baroque aesthetics. The fragmentation of the speech, breaking with the narrative unity, and the dispersal of the truth, taken like a multiplicity of versions, are the ways of reading that drive us to the labyrinth proposed by the author: image of a non-centered world.

KEYWORDS: Truth; dissipation; fragmentation; neo-baroque aesthetics 
“Atenção!” Um leitor ingênuo, diante da sinopse de A Corte do Norte que "parte" da morte de Rosalina de Souza, baronesa de Madalena do Mar, como enigma-condutor da narrativa - possivelmente acreditará ter em mãos um daqueles romances policiais, no estilo best seller inglês, em que um crime serve de mote para um enredo misterioso a ser desvendando no fim. $O$ fio condutor desse gênero é a sequência das pistas do narrador na montagem de um quebra-cabeças que revelará o assassino e as circunstâncias criminais. Em A Corte do Norte, a morte de Rosalina, anunciada nas primeiras páginas, é de fato um enigma, mas que conduz o leitor não à procura dos elementos de um suposto crime, mas em busca de uma suposta autoria.

A pergunta "Quem matou Rosalina?", apresentada como pretexto para prosseguir a narrativa, vai sendo gradativamente substituída por "Quem pode escrever a história de Rosalina (ou - metonimicamente - de todo personagem)?" E o que seria um quebra-cabeças se apresenta então como um mosaico. Tentando encaixar as peças para formar uma figura una, indivisível e equilibrada, o leitor acabará por conhecer a beleza do incompleto, do impreciso, do metamórfico. E transitará não por um caminho de pedras que levam João e Maria ao seu destino, mas por um desconcertante labirinto de onde não se sai a não ser pela resignação - viver é percorrer labirintos.

No revelar-se do jogo labiríntico é que reside a intriga (e a complexidade) do romance de Agustina. Os personagens vão sendo apresentados sucessivamente e ocupam o "palco" definido pela autora - a ilha da Madeira, mais especificamente na região da Corte do Norte. A passagem do tempo, com a sucessão de gerações que entram e saem de cena, garante o que mais se aproxima de uma linearidade no texto, já que as experiências de cada personagem são de tal modo independentes que se tem a impressão de estar diante de uma variedade de histórias e gêneros textuais, como se o livro estivesse sempre recomeçando sem concluir as ações conhecidas anteriormente. As "histórias" incompletas e aparentemente desconexas vão sendo alinhavadas por um jogo da memória em que, por hipóteses, buscam-se paridades alegóricas entre personagens, imagens e experiências. E o súbito interesse dos descendentes de Rosalina em desvendar o enigma de sua morte vai permitindo encaixes na narrativa, o reconhecimento de que embora os fragmentos narrativos sejam unidades autônomas e amorfas - e não puzzles similares - eles possuem uma estrutura nuclear, um centro de onde partem e para onde podem retornar. Metafórica e metonimicamente é que se dão as relações semânticas que garantem a unidade de $A$ Corte do Norte. Aos poucos, o leitor (maduro) vai se dando conta de que não está diante de um romance sobre a vida de Rosalina ou de "quem-quer-que-seja", mas de um "making of" literário, um romance sobre a dissipação da linguagem e sua precariedade (que é riqueza) na determinação da "verdade" sobre os fatos narrados.

A dispersão das versões sobre o enigma de Rosalina é alegoria da própria criação literária ou do processo discursivo, revela a potencialidade infinitamente desdobrável do pensamento a partir de hipóteses precedentes. A morte de Rosalina é a morte do referente no texto. O leitor é convidado a abandonar sua posição passivo-receptora para entender que por detrás (e apesar) das palavras autorais há um vazio que precisa ser preenchido. É na ausência - e sobre a ausência - que se constrói o romance de Agustina. Ausência de uma versão enunciada sobre os fatos narrados, ausência do narrador como centralizador da verdade, onisciência suprema sobre o destino e a origem. O narrador de $A$ Corte do Norte admite desconhecer os elementos que supostamente montariam de modo ordenado e racional a sua história, que elucidariam os fatos e organizariam as relações de causa-e-efeito propostas no 
enredo. O prazer na leitura de $A$ Corte do Norte está em participar da maquinaria do texto, entender seus desvios e descaminhos, desvendar o ilusionismo que a cenografia no palco teatral proporciona a quem não conhece a coxia.

É nas lacunas que há na história de cada personagem - e no mosaico das histórias aproximadas em uma pretensa unidade textual - que o leitor é convidado a adentrar e explorar. $A$ Corte do Norte vai em direção ao que não há a partir do que há. Ou, como diz o narrador, "O que trata este livro é o sentimento insular que se instaura no uso da saudade, como algo que tudo invade e imobiliza. Como uma forma civilizadora e, no entanto, precária (BESSA-LUÍS, 1996, pp. 14-15)." Imagine-se a cena: Sherlock Holmes, convidado a destrinchar o caso Rosalina, diante de tantos suspeitos, pronto à revelação dos elementos criminais, declara:

Não há enigma a ser desvendado. O destino de Boal era uma linguagem, o mistério dela era uma forma de fornecer às pessoas um fio condutor que as levasse até ela. O enigma não existe enquanto libertação da linguagem. Rosalina não morreu porque nunca existiu. Tudo aqui é linguagem. ${ }^{1}$

Holmes, adepto do método cartesiano baseado na clareza e na distinção - que utiliza a indução e a dedução como recursos lógicos de eficácia para apreensão de uma solução silogística -, diante do caso escrito por Agustina, render-se ia ao que Umberto Eco, em uma leitura de Charles Peirce, chama de método da abdução. Esse recurso consiste na apreensão de muitas verdades a partir de uma hipótese sujeita a interpretações, que, assim como qualquer premissa abdutiva, podem sempre falhar, já que representam "o propósito, a tentativa arriscada, de um sistema de regras de significação à luz das quais um signo adquirirá o seu significado" (PEIRCE, apud ECO, 1994, p. 39).

\section{Um mundo descentrado}

"A vida não é para os que a compreendem, é para os que a praticam" (BESSA-LUÍS, p. 200). Estamos em um ambiente - dizem as entrelinhas desse recorte aforístico do romance - onde não se pretendem objetos prontos e acabados, mas processos. A autora, pelo viés literário, representava o olhar de seu tempo. Em 1987 - data da primeira edição do livro -, coincidentemente, Omar Calabrese publicava A Idade Neobarroca. Ao definir uma "nova" mentalidade da sociedade contemporânea e as suas implicações na arte e na cultura de massa, o autor apontava: vivemos uma era "em que assistimos à perda da integridade, da globalidade, da sistematicidade ordenada em troca da instabilidade, da polidimensionalidade, da mutabilidade" (CALABRESE, 1988, p. 10). Essa "nova" mentalidade retratava, nas observações do autor, uma sociedade esfacelada pelo sentimento de crise, descentrada de suas convicções sobre o ser e estar sociais.

O mundo descentrado representado pela arte contemporânea vinculase, por analogia, à sociedade seiscentista e à sua estética barroca definida como "uma arte de crise, mas não uma arte da crise; [que] expressa uma mentalidade, não uma consciência" (MARAVALL, 1997, p. 248). A arte barroca - de ontem e de hoje - é fruto (e não discussão) da perda do "ponto de equilíbrio" social, de um eixo, de um centro lógico organizador do pensamento - aspectos que poderiam ser tomados como base para o entendimento sobre os próprios rumos. Nas palavras de Maravall, o ambiente barroco se assemelha a "um 
confuso labirinto" (MARAVALL, 1997, p. 253), de caminhos fragmentados e decompostos; ou pode ser igualmente percebido "como estalagem" (MARAVALL p. 254), passagem transitória e fugaz; ou ainda se mostra "como teatro" (MARAVALL, p. 255), em que são evidentes "o caráter transitório do papel designado a cada um", "o rodízio na distribuição de papéis" e também a valorização da "condição aparencial" da vida, do espaço cênico e da composição humana.

Severo Sarduy, outro teórico da estética referida, define que "o barroco moderno, o neobarroco, reflecte estruturalmente a discordância: a ruptura da homogeneidade, a ausência de um Logos absoluto, a carência em vez do fundamento como episteme" (SARDUY, 1989, p. 96). O escritor neobarroco desafia as referências da composição do texto e assinala sua presença no recurso da metalinguagem. A onisciência do narrador, os limites definidores de um personagem, a categoria textual, o gênero artístico, tudo está ameaçado pela corrosão da linguagem. Há, no neobarroco, um "reflexo necessariamente pulverizado de um saber que sabe não se encontrar já 'tranquilamente' fechado sobre si mesmo." (SARDUY, 1989, p. 97)

A Corte do Norte rompe com o "Logos absoluto", na medida em que se apresenta como uma "trama aberta, sem referência a um significante privilegiado que a oriente e lhe confira sentido" (SARDUY, 1989, pp. 61-62). Seu "saber" é pulverizado, dissipa-se nas incertezas autorais e transborda incompleto, impreciso ao leitor, que segue um dispersivo percurso à procura de respostas, de preenchimentos lógicos que - numa busca ao infinito - vão em direção a uma suposta relação lógica linear, que nunca se faz. Como perfeito exemplar neobarroco, o livro de Agustina Bessa-Luís traz a dissipação e a fragmentação da linguagem como fio condutor de um enredo em construção, que assim se apresenta não por carecer de recursos de linearidade, mas por representar geometricamente - com precisão - o mundo à sua volta.

\section{Primeiros passos de um labirinto}

O jogo proposto ao leitor, no romance aqui observado, exigirá do "participante" uma consciência de seus passos percorridos, de modo que não lhe será imputado mergulhar no enredo sem a convicção plena de sua posição interlocutória. Transitar um labirinto, diferentemente do que ocorre quando se navega em linha reta, exige atenção redobrada e não permite ao timoneiro esquecer que há um rumo a ser seguido. Abramos o livro de Agustina BessaLuís, portanto, atentos às primeiras pistas que a leitura nos sugere.

"João Gomes, conhecido por Trovador, que casou no Funchal com a filha dum companheiro de Gonçalves Zarco, foi homem de cuidados e suspiros." (BESSA-LUÍS, 1996, p. 7) Assim o leitor é apresentado a $A$ Corte do Norte e está prestes a percorrer o que descobrirá ser uma imbricada trajetória textual. Entenderá que não está num caminho contínuo que leva ao fim da estrada somente quando se der conta dos descaminhos do texto, suas pistas de dispersão. A primeira delas, a esta altura, já está posta em jogo. João Gomes é um quase-personagem que se apresenta à ponta do livro. Seu súbito desaparecimento, na leitura sequente, dará origem a um questionamento: o que veio fazer no texto um João Gomes que não "servirá" ao enredo? O pseudopersonagem "responde" com um poema-alegoria: "Da lembrança do passado / com desejo do futuro / em o tear do cuidado / se tece mui restorçado / terçopelo verde escuro" (BESSA-LUÍS, 1996, p. 7). E a autora, em exercício metalinguístico proposto pelo narrador, nos alerta: "Para entender este romance é preciso entender a linguagem nobre que foi prelúdio da poesia 
mística castelhana" (BESSA-LUÍS, 1996, p. 7) - que aqui está representada pelos versos de João Gomes. Está lançado o desafio. Há um tear bem cuidado, retorcido, reforçado a compor a tessitura do texto que aqui (ali) se apresenta. Uma linguagem nobre, rebuscada e imbricada em detalhamento e complexidade semântica. Atenção! - diz (sem dizer) a autora - Este romance é indicado a quem espera por densidade e rebuscamento estético. Não por acaso, em entrevista ao jornalista Arthur Portela, Agustina Bessa-Luís assim define seus leitores (ou o que imagina deles): "Encontro-os por todo lado. Gente das letras, burgueses um bocado complicados a quem a vida desilude e o coração oprime; jovens a quem a heroicidade do talento comove sempre" (BESSALUÍS \& PORTELA, 1986, p. 11).

Após “abandonar" João Gomes, o narrador de $A$ Corte do Norte põe o foco de luz na outrora Imperatriz da Áustria Elizabeth. Durante algumas páginas, conta-nos sobre a visita de Sissi à Madeira - palco da narrativa - com detalhadas descrições. Envolvidos com as histórias da Imperatriz, quando já acreditamos - nós, leitores - estar "acompanhando" a primeira personagem do texto, temos nova revelação: "Mas este não é um romance da formosa Imperatriz, nem a história das suas vicissitudes clínicas ou familiares." (BESSA-LUÍS, 1996, p. 14-15) Eis uma nova desmontagem de nossas expectativas e, ao mesmo tempo, uma "pista" para o caminho tortuoso que o livro nos apresenta. "Não vão por aí!" - adverte-nos. Em nossa formação de leitura romanesca, tendemos a aguardar passivamente a entrada de um protagonista e sua ocupação de cena - delimitação espaço-temporal. Nesse romance de Agustina, diante de personagens que não "assumem" o enredo, temos que aceitar o vazio da ocupação cênica. "É isso aí!" - quer nos dizer a autora - "Vamos ficar com o vazio".

Eis que surge Rosalina de Souza. E aparentemente finca a bandeira em nosso território oco. "É ela! Chegou!" - pode parecer. Na verdade, Rosalina é de fato o que mais se aproxima de uma personagem principal no texto. Ela será o fio de costura de todas as relações humanas e/ou simbólicas apresentadas no romance. Sua ocupação de cena é definitiva, já que seu nome será lembrado do primeiro ao último capítulo do livro, mas sua importância se dará por ausência e não por presença. Ao final do primeiro capítulo, a morte de Rosalina é o anúncio definitivo de que o leitor deverá se satisfazer não com o encontro de uma protagonista, mas com as lacunas de um enredo à procura de um personagem que o sustente: "A história parece terminar aqui, uma vez que nos propusemos a ser a história de Rosalina. Mas aqui começa apenas o enigma e seus ornamentos" (BESSA LUÍS, 1996, p. 33). A ornamentação a partir de um enigma, em substituição a um projeto lógico-linear de descrição e esclarecimento de um suposto mistério, traduz o barroquismo estético proposto na arquitetura textual. O vazio será preenchido por ornamentos, o que tornará mais difusa e opaca a leitura do texto fundador do enigma.

\section{Colhendo pistas que despistam}

Quem matou e como morreu Rosalina? Como em um arranjo de quebra-cabeças, o narrador vai fornecendo "informações" sobre seu proposto (e suposto) mistério, como se o enigma estivesse sendo reconstituído a partir da elucidação de fatos. O leitor colhe as "pistas" sobre o fim de Rosalina. Inicialmente, a versão apresentada revela de modo insuspeito a morte acidental da personagem, que "despenhou das falésias" (BESSA-LUÍS, 1996, p. 33) e se perdeu no mar. Não haveria, então, suspense algum, não fossem as versões díspares e aparentemente incoerentes sobre o fato, que acabam por criar 
alternativas ao que já se havia tomado por verdade. Haveria Rosalina saído da ilha, secretamente, "usando outra identidade" (BESSA-LUÍS, 1996, p. 64). Ou "estava enterrada na capela nos Sanha" (BESSA-LUÍS, 1996, p. 96). Ou, num sopro da África, "fora decerto o vento que a derrubara dos penhascos" (BESSA-LUÍS, 1996, p. 98). Ou morrera de "doença epidêmica" e, secretamente, "fora enterrada pelo marido" (BESSA-LUÍS, 1996, p. 119). As hipóteses começam a se multiplicar sem que haja, por parte do narrador, qualquer definição ou mesmo a aceitação do desconhecimento sobre os fatos. O leitor aguarda pela onisciência narrativa e é traído por um narrador que é assertivo na dúvida, que embarca em todas as versões sobre a "protagonista" e as defende com a veemência de quem afinal descobre a razão. Passeando pelos pensamentos das personagens, o narrador delega a autoria da história de Rosalina aos muitos sujeitos capazes de constituir uma verdade e, dessa forma, ensaia a impossibilidade de se apreender o que seria uma verdade universal sobre o fato.

O jogo de versões, orquestrado pela autora, no entendimento de Silvina Rodrigues Lopes, produz "um movimento de dissipação que, ao mesmo tempo que no-la dá a ver nas suas múltiplas imagens, desgasta, torna fluida e inapreensível qualquer imagem final" (LOPES, 1992, p. 86) E, embora se possa admitir para alguns "uma decepção quanto aos resultados em termos de investigação policial" (LOPES, 1992., p. 86) , por outro lado "é essa estratégia que faz da história de Rosalina uma multiplicação de perspectivas sedutoras como exercício da imaginação" (LOPES, 1992, p. 86). Afinal, ouvindo as palavras de Calabrese, "Não existe, aliás, enigma mais divertido do que aquele acerca do qual se supõe uma solução, mas cuja solução jamais acontece." (1988 p. 156)

As histórias dos filhos, netos, bisnetos, tataranetos vão entrecortando a narrativa, espaçando a produção de hipóteses sobre a vida e a morte da matriarca da linhagem Barros, e, quanto mais distante vai se tornando o mistério de Boal em relação ao tempo narrado, mais embaçada e desfocada se capta sua imagem. Rosalina vai se "desfigurando" (BESSA-LUÍS, 1996, p. 150), perdendo a sua estrutura corpórea, "lança-se ao ar" imaginando que "pode voar" (BESSA-LUÍS, 1996, p. 173), "desafia a lei da gravidade", "desprende-se do ser" e "torna-se linguagem" (BESSA-LUÍS, 1996, p. 200). A partir de sua morte, Rosalina sofre, portanto, um gradual processo de despersonificação. A cada retomada de seu nome, através da lembrança de seus sucessores, nas versões cada vez mais escabrosas para explicar o seu fim, ou a cada suspeita do narrador de que ela possuía outra identidade - era a atriz Emília de Souza ou a Imperatriz Sissi -, Rosalina vai se transformando em mito até virar símbolo, mero produto de linguagem.

\section{Por onde se chega ao fim?}

Recomeçar é um movimento que a engenharia de todo labirinto requer de suas "vítimas". Recomeça-se o percurso sempre que se percebe não ter achado um caminho seguro que conduza a um certeiro fim. Em $A$ Corte do Norte, novos personagens - de sucessivas gerações, que adentram a narrativa com histórias próprias e contribuições até então inimagináveis sobre a morte da matriarca dos Barros - compõem a "planta-baixa" de uma arquitetura fragmentária e dispersiva percorrida por um leitor em busca de um fio condutor. Toda vez que fixa seus olhos sobre a vida de um personagem, esse leitor é interrompido pelo súbito aparecimento de outro e se vê num emaranhado lógico que desestabiliza sua confortável posição de recepção da 
mensagem romanesca. Quem é esse novo personagem? Como termina a história daquele que eu acompanhava antes? Quem sabe a verdade sobre Rosalina? Afinal, por onde se chega ao fim?

"O epílogo desta história não se há-de escrever nunca" (BESSA-LUÍS, 1996, p. 271), diz o narrador de Agustina Bessa-Luís. Se, fisicamente, as últimas páginas de todo livro sugerem um desfecho, evidentemente aguardado pelo leitor no que se refere ao enredo por ele percorrido, há que se advertir que, nesse romance, existe uma incapacidade de concluir uma trama que mal chegou a ser delineada. Afinal, como afirma o narrador, revestindo-se da condição de autor(a) do romance, "vi muitas gentes e muitas verdades; e, com estas, lendas e adivinhações. De tudo, fiz este livro" (BESSA-LUÍS, 1996, p. 273). Um livro, portanto, de muitas verdades, de lendas e adivinhações, deverá ser um livro sem um único e perfeito eixo axiológico, retrato fiel de um mundo descentrado. Ao leitor restará aceitar a resposta da incompletude e o desacerto que advém de se conviver com a dúvida, gerada por um universo polissêmico.

A quem me perguntar se de facto Emília de Souza teve a vida dupla de Rosalina, baronesa de Madalena do Mar, eu vou responder à maneira de Garrett quando, depois da estreia do Auto de Gil Vicente, quiseram saber se Bernardim se atirara ao mar e realmente se afogara, ao ver desaparecer a nau que levava a princesa para sempre dos seus olhos:

- Isso não é comigo. Pergunte ali ao contra-regra, que ele é que está em condições de responder (BESSA-LUÍS, 1996, pp. 273274).

Fica assim posta a última pedra que encerra qualquer expectativa por uma elucidação narrativa sobre a trama proposta. A um leitor ingênuo, último dos moicanos, que a essa altura pensasse - influenciado pelas determinações cinematográficas do nosso século - "vão lançar a parte 2", fica assim registrado o fim sem fim. Não há solução. Ou melhor, a solução é a de não haver solução. Os descaminhos propostos por Agustina fazem parte de uma engenharia textual que reproduz um mundo onde já não se pensa a solidez ou a unicidade do caminho. Um mundo líquido, define Bauman, em que já não se crê em uma "solidez em que se pudesse confiar e que tornaria o mundo previsível e, portanto, administrável" (BAUMAN, 2001, p. 10). A escrita literária, espelho da sociedade que a produz, igualmente se liquefaz, diluindo as certezas outrora reiteradas por um texto unificado, coeso e coerente, tecido por convicções bíblicas. No mundo disperso e descentrado, impera a polissemia e a polifonia bakhtiniana. A verdade enunciada é corroída pelas versões entrecortadas, expostas ao leitor de modo fragmentado, para que nele se constitua um texto possível. Rosalina, produto literário, é mero instrumento de linguagem, verbete enciclopédico, simples na forma e complexo no sentido, pela pluralidade semântica a que todo signo está sujeito. Estará morta quando esquecida, mas renascerá cada vez que um novo leitor - ficcional ou real - se interessar pela sua história e redescobrir a "trama aberta", expressão de Sarduy já aqui apontada, que constitui a sua (e toda) biografia. 


\section{NOTAS}

1. O trecho entre aspas, atribuído ludicamente a Sherlock Holmes, é uma colagem de frases retiradas da narrativa de $A$ Corte do Norte: "Rosamund percebeu que o destino de Boal era uma linguagem, que o mistério dela era uma forma de fornecer às pessoas um fio condutor que as levasse até ela."(p. 200) / "O enigma não existe enquanto libertação da linguagem” (p. 241).

\section{REFERÊNCIAS BIBLIOGRÁFICAS}

BAUMAN, Zygmunt. Modernidade líquida. Trad. Plínio Dentzien. Rio de Janeiro: Jorge Zahar, 2001.

BESSA-LUÍS, Agustina, \& PORTELA, Arthur. Agustina por Agustina. Lisboa: Publicações Dom Quixote, 1986.

BESSA-LUÍS, Agustina. A Corte do Norte. Lisboa: Guimarães, 1996.

ECO, Umberto, 1994, "O Signo", in Enciclopédia Einaudi, Vol. 31 (O Signo), Lisboa: Imprensa Nacional - Casa da Moeda, pp. 11-51.

LOPES, Silvina Rodrigues. Agustina Bessa-Luís: as hipóteses do romance. Rio Tinto: Asa, 1992.

MARAVALL, Jose Antonio. A cultura do barroco: analise de uma estrutura histórica. São Paulo: EDUSP, 1997.

SARDUY, Severo. Barroco. Lisboa: Veja, 1989. 